\title{
The Quadrennial Ozone Symposium 2016
}

\author{
Sophie GODIN-BEEKMANN ${ }^{1}$, Irina PETROPAVLOSKIKH ${ }^{2}$, Stefan REIS ${ }^{3,20}$, Paul NEWMAN ${ }^{4}$, \\ Wolfgang STEINBRECHT ${ }^{5}$, Markus REX ${ }^{6}$, Michelle L. SANTEE ${ }^{7}$, Richard S. ECKMAN ${ }^{8}$, \\ Xiandong ZHENG ${ }^{9}$, Matthew B. TULLY ${ }^{10}$, David S. STEVENSON ${ }^{11}$, Paul YOUNG ${ }^{12}$, \\ John PYLE ${ }^{13}$, Mark WEBER ${ }^{14}$, Johanna TAMMINEN ${ }^{15}$, Gina MILLS ${ }^{16}$, Alkis F. BAIS ${ }^{17}$, \\ Clare HEAVISIDE ${ }^{18}$, and Christos ZEREFOS ${ }^{19}$ \\ ${ }^{1}$ Observatoire de Versailles Saint-Quentin en Yvelines, Université de Versailles Saint-Quentin-en-Yvelines, \\ CNRS, 78280 Guyancourt, France \\ ${ }^{2}$ CIRES, University of Colorado, Boulder, CO 80309, USA \\ ${ }^{3}$ NERC Centre for Ecology \& Hydrology, Edinburgh EH26 OQB, UK \\ ${ }^{4}$ Goddard Space Flight Center, NASA, Greenbelt, MD 20771, USA \\ ${ }^{5}$ Hohenpeissenberg Meteorological Observatory, Deutscher Wetterdienst, 82383 Hohenpeissenberg, Germany \\ ${ }^{6}$ Alfred Wegener Institute, 14401 Potsdam, Germany \\ ${ }^{7}$ Jet Propulsion Laboratory, California Institute of Technology, CA 91109, USA \\ ${ }^{8}$ NASA Headquarters, Earth Science Division, Washington, DC, USA \\ ${ }^{9}$ Chinese Academy of Meteorological Sciences, Beijing, 100081, China \\ ${ }^{10}$ Bureau of Meteorology, Melbourne, Victoria 3001, Australia \\ ${ }^{11}$ University of Edinburgh, School of GeoSciences, Edinburgh EH9 3FE, UK \\ ${ }^{12}$ Lancaster Environment Centre, Lancaster University, Lancaster LA1 4YQ, UK \\ ${ }^{13}$ University of Cambridge, Department of Chemistry, Cambridge CB2 1EW, UK \\ ${ }^{14}$ University of Bremen, Institute of Environmental Physics, 28359 Bremen, Germany \\ ${ }^{15}$ Finnish Meteorological Institute, Earth Observation, FI-00101 Helsinki, Finland \\ ${ }^{16}$ NERC Centre for Ecology and Hydrology, Bangor, Gwynedd LL57 2UW, Wales, UK \\ ${ }^{17}$ Aristotle University of Thessaloniki, ELKE AUTH, Thessaloniki, Greece \\ ${ }^{18}$ Public Health England, Centre for Radiation, Chemical and Environmental Hazards, London, UK \\ ${ }^{19}$ Research Center for Atmospheric Physics \& Climatology, Academy of Athens, Athens 10680, Greece \\ ${ }^{20}$ University of Exeter Medical School, Truro TR1 3HD, UK
}

(Received 9 December 2016; accepted 19 December 2016)

Citation: Godin-Beekmann, S., and Coauthors, 2017: The Quadrennial Ozone Symposium 2016. Adv. Atmos. Sci., 34(3), 283-288, doi: 10.1007/s00376-016-6309-2.

\section{Overview}

The 2016 Quadrennial Ozone Symposium (QOS-2016) was held on 4-9 September 2016 in Edinburgh, UK. The Symposium was organized by the International Ozone Commission (IO3C), the NERC Centre for Ecology \& Hydrology and the University of Edinburgh, and was co-sponsored by the International Union of Geodesy and Geophysics, the International Association of Meteorology and Atmospheric Sciences, and the World Meteorological Organization. More than 300 participants from 39 different countries attended the Symposium (Fig. 1). There were 6 keynote talks, 75 oral presentations and 270 poster presentations. QOS-2016 covered the breadth and depth of atmospheric ozone observations and research. Key topics included: stratospheric and tropospheric ozone observations and modelling; interactions be- tween ozone, atmospheric chemistry and climate; ozone measurement techniques; and effects on human health, ecosystems, and agriculture. Engagement with stakeholders and policymakers was another key feature of QOS2016. The Symposium was opened by L. HEATHWAITE, Chief Scientific Advisor of Rural Affairs and Environment to the Scottish Government, and the Symposium's final day included two talks on the "Future challenges for stratospheric and tropospheric ozone", followed by a moderated panel discussion on policy issues related to atmospheric ozone.

\section{Stratospheric ozone}

Session 1 of the Symposium focused on stratospheric ozone, its long-term evolution and trends, polar ozone in recent winters, exchange processes between the lower strato- 


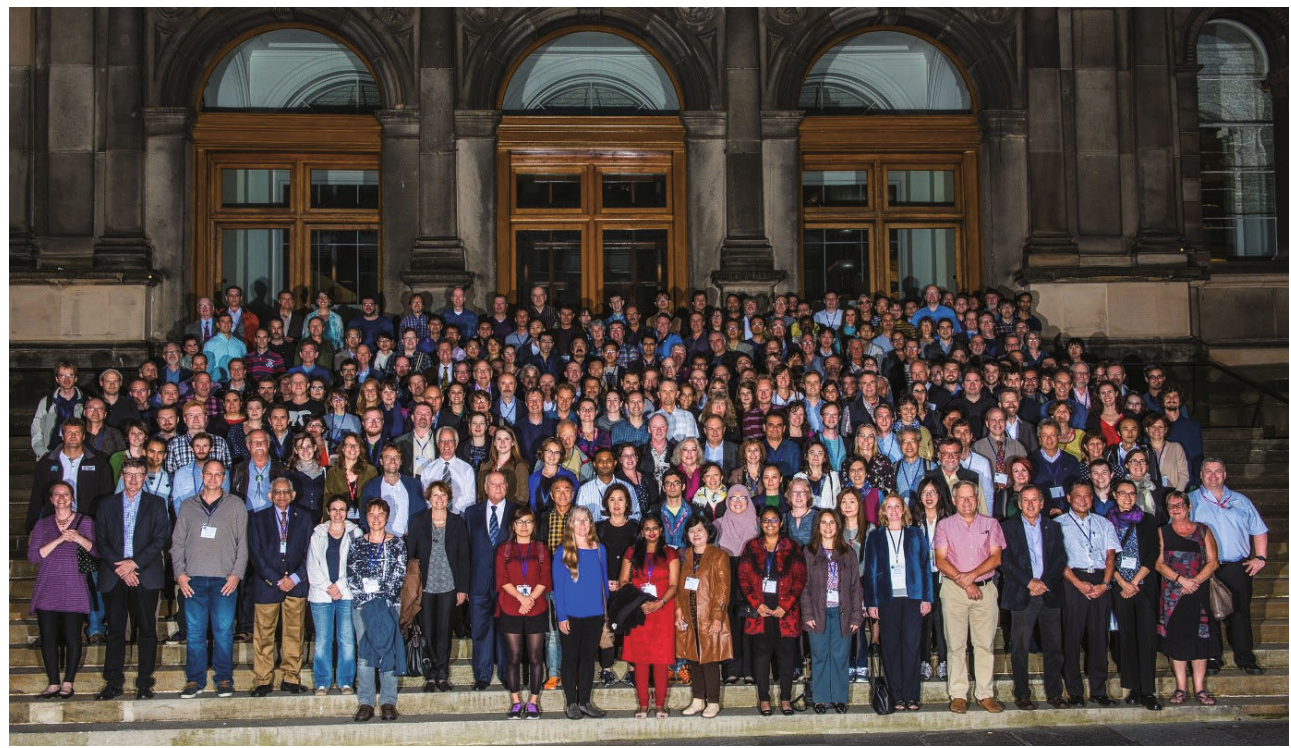

Fig. 1. Group picture of the QOS2016 participants.

sphere and the troposphere, and various other dynamical and chemical aspects. This opening session had 23 oral talks, and 90 poster presentations.

In the session's invited keynote talk, P. A. NEWMAN (USA) showed the reductions in ozone depleting substances (ODSs) that have been achieved by the Montreal Protocol and its amendments. ODSs are also strong greenhouse gases, so global climate has also benefited considerably from the Montreal Protocol. To avoid losing these benefits, the parties to the Montreal Protocol agreed in October 2016 to ban hydrofluorocarbons (HFCs), which are used as ODS replacements, but have high global warming potential. Since ODSs are declining, the general expectation is for a recovery of ozone to 1980 levels over the coming decades before the end of the century. By that time, ozone changes due to increasing $\mathrm{CO}_{2}, \mathrm{CH}_{4}$ and $\mathrm{N}_{2} \mathrm{O}$ might become comparable in size to the current ozone depletion by ODSs. This makes it important to follow the evolution of these gases and to better understand their effects on the ozone layer and its expected recovery.

For the Antarctic ozone hole, S. SOLOMON (USA) and J. de LAAT (Netherlands) reported first indications of the beginning of a recovery. However, model studies presented by S. STRAHAN (USA), as well as satellite observations analyzed by M. SCHWARTZ (USA), show that several more years of observations are necessary before really robust signs of Antarctic (or Arctic) ozone recovery can be expected. Polar stratospheric clouds (PSCs) play a key role in polar ozone depletion. R. SPANG (Germany) and M. PITTS (USA) gave overviews based on PSC measurements from the space-borne MIPAS (Michelson Interferometer for Passive Atmospheric Sounding) infrared spectrometer and CALIPSO (Cloud-Aerosol Lidar and Infrared Pathfinder Spaceborne Observations) lidar, respectively. The Arctic winter of 2015/16 was exceptionally cold, leading to widespread PSCs, and even ice-PSCs, which are rare in the Arctic. Accordingly, F. KHOSRAWI (Germany) reported substantial denitrification and dehydration by sedimentation of PSC particles. Initial ozone losses were also large, e.g. in MATCH (The Match method quantifies chemical ozone loss in the polar stratosphere by probing air parcels in the polar vortex by coordinated ozone sondes). ozonesonde analyses. Fortunately, a large stratospheric warming in February 2016 prevented severe large-scale ozone loss. Many aspects of this winter, and also the context of previous winters, were covered in other talks and posters.

Ozone trends and the search for ozone recovery signs were the topic of many talks and posters: B. WEATHERHEAD (USA) pointed out that statistical analysis alone cannot provide the answer. Rather, a synopsis of our understanding based on modeling results, observations, careful analyses and a priori information is required. So far, significant signs of increasing ozone have been seen in the upper stratosphere only. D. HUBERT (Belgium) gave a comprehensive overview of the difficulties in quantifying trends and their accuracy from existing satellite and ground-based ozone records.

The tropical upper troposphere and lower stratosphere remain very interesting regions. Not only are they affected by changes in global atmospheric transport by the BrewerDobson circulation, but they are also the main entry point for source gases into the stratosphere. Talks and posters highlighted decadal variations in this region, diagnosed in ozone data (L. FROIDEVAUX, USA), in age-of-air (G. STILLER, Germany), and in other parameters. For example, very shortlived chlorine-, bromine-, and iodine-carrying substances in the tropics play an important role, as shown by R. HOSSAINI (UK) and D. ORAM (UK). M. HEGGLIN (UK) noted that possible increases in tropospheric ozone over recent decades could have offset the stratospheric ozone loss in the tropical 
belt, and thus could explain the long-standing discrepancy between model-simulated and observed total ozone trends in the tropics. Unfortunately, good long-term observations of ozone in the free troposphere are lacking, especially in the tropics. This was a good lead-in to the next session dealing with tropospheric ozone.

\section{Tropospheric ozone}

As an important oxidant and short-lived climate forcing gas, tropospheric ozone plays a significant role in Earth's atmospheric processes. It is also a pollutant affecting human health, agriculture and ecosystems. The Symposium's tropospheric ozone session featured presentations that addressed trends in tropospheric ozone derived from both observations and models. Analysis of climate change, transport, emissions, dry deposition and chemical oxidative processes that have direct and indirect effects on tropospheric ozone variability were also discussed during both the oral sessions and across a wide range of poster presentations.

In the session's invited keynote talk, O. COOPER (USA) covered topics of evolving trends in tropospheric ozone burden and ozone long-range transport mechanisms, and its impact on human health and vegetation. The presentation emphasized the shift of a large portion of the anthropogenic emissions from North America and Europe to Asia since the 1990s. These shifts correspond to the observed changes in the global distributions of elevated tropospheric ozone concentrations. On these topics, the International Global Atmospheric Chemistry Project has recently initiated the Tropospheric Ozone Assessment Report (TOAR) project, which aims to answer important science- and society-relevant questions on current and future levels in the global tropospheric ozone burden.

J. NEU (USA) presented a review of the stratospheric contribution to tropospheric ozone variability and trends, as predicted by models and observed by satellites and groundbased measurements. She discussed the effects of the seasonal timing of the stratospheric Quasi-Biennial Oscillation and El Niño-Southern Oscillation on stratospheric circulation and the tropospheric ozone response. In order to understand variability in the ozonesonde-sampled data, R. STAUFFER (USA) demonstrated the advantages of using a statistical clustering technique called self-organizing maps, over simple averaging. D. FLITTNER (USA), previewed NASA's upcoming TEMPO (Tropospheric Emissions: Monitoring of Pollution) geostationary satellite mission, which will support studies on the key elements of tropospheric air pollution chemistry.

Next, the discussion moved on to anthropogenic aerosol characteristics and their influence on photochemical pollution in the Pearl River Delta region, China (X. J. DENG, China). Y. KANAYA (Japan) discussed in situ ozone production rates at Fukue in Japan, including the $\mathrm{NO}_{\mathrm{x}}$ and VOC (volatile organic compound) limiting factors that control additional ozone production. Future challenges include a better understanding of the whole chemical system, including the production of radicals and how the stabilizing levels of pollution over China will influence the currently high ozone levels. R. CHATFIELD (USA) told the audience that there are many open questions remaining in the research field of assessing tropospheric ozone production from extratropical forest fires. K. PICKERING (USA) gave an overview of the ability of satellites to provide air quality relevant information. He also gave an analysis of four DISCOVER-AQ campaigns, aimed at collecting ozone enhancements over polluted regions in the U.S. and associated precursor data. K.-P. HEUE (Germany) presented tropospheric ozone trends derived from the new convective cloud differential method applied to GOME 2 (Global Ozone Monitoring Experiment-2) satellite data, and compared them with other tropospheric ozone datasets that combine satellite total column and stratospheric ozone measurements. Y. COHEN (France) discussed statistically significant positive trends in the ozone upper troposphere, of the order of $0.3 \%-0.5 \% \mathrm{yr}^{-1}$, over northern midlatitudes, as observed by MOZAIC-IAGOS (Measurement of Ozone and Water Vapour on Airbus in-service Aircraft-In-service Aircraft for a Global Observing System), over the period 19952013. Upper troposphere-lower stratosphere ozone levels were found to show significant increases. These tendencies were not linked to a particular season and were influenced by the increase of the lowest values.

The session's last section started with the question: "How well do we know global long-term tropospheric ozone changes?" This question was posed by D. TARASICK (Canada) to evaluate the quality of historical datasets as part of the TOAR project. C. WESPES (France) provided an overview of geographical ozone variability in the troposphere available from IASI (Infrared Atmospheric Sounding Interferometer) observations from 2008 to 2015. She noted the direct effects of the North Atlantic Oscillation and moderateto-intense El Niño episodes in 2009 and 2015, and La Niña in 2010, on the observed levels of tropical ozone columns. K. A. MAR (Germany) used 20 years of European ozone air quality observations to indicate that peak episodic ozone decreased in Europe over the period 1990-2010, while annual average ozone was found to increase until 2000 and decrease afterwards. Analysis by M. J. GRANADOS-MUÑOZ (USA) of tropospheric ozone based on long-term lidar observations and surface ozone monitoring at a high elevation remote site, with no influence of urban pollution, JPLTable Mountain, California, showed that larger ozone values were associated with stratospheric transport, while minimum values were transported from the Pacific. E von SCHNEIDEMESSER (Germany) discussed the TOAR findings that are relevant for human health. She mentioned that urban surface ozone measurement sites in East Asia show predominantly increasing trends in air-quality violations, while the air quality is improving in Europe and North America. The concluding talk by T. TRICKL (Germany) was about the LUAMI (Lindenberg Upper-Air Methods Intercomparison) project, which improved understanding of the tomography of a deep stratospheric air intrusion over Central Europe on 17 October 2008. 


\section{Ozone chemistry-climate interactions}

The Symposium's third session was dedicated to the interactions between ozone chemistry and climate. Changes in ozone influence climate directly, by affecting fluxes of both solar and terrestrial radiation, or temperature in the stratosphere; but also indirectly, via effects of ozone on vegetation and the carbon cycle, or via changes in the oxidizing capacity of the atmosphere and hence the budgets of other greenhouse gases. Conversely, changes in climate affect ozone, with temperature changes influencing reaction rate coefficients and absolute humidity, by climate-dependent emissions of ozone precursors, and through changes in atmospheric circulation (e.g., the Brewer-Dobson circulation). These interactions induce potentially large feedbacks in the climate system.

The session's keynote lecture by K. SUDO (Japan) focused on the understanding of interannual variability and trends in global tropospheric ozone during recent decades using global and regional modelling. In recent decades, changes in emissions have played a substantial role in ozone increases in Asia; while in other regions, tropospheric ozone changes appear to have been controlled by climate change and stratospheric ozone evolution through enhanced stratosphere-troposphere exchange. Subsequent presentations addressed the influence of atmospheric ozone changes on climate and, conversely, the impact of climate change on future ozone evolution. With respect to the latter, L. E. REVELL (Switzerland) talked about the changing ozone depletion potential of $\mathrm{N}_{2} \mathrm{O}$ in a future climate, in relation with the fact that $\mathrm{NO}_{x}$-induced ozone loss slows with increasing concentrations of $\mathrm{CO}_{2}$ and $\mathrm{CH}_{4}$. A. H. BUTLER (USA) addressed the diverse policy implications for future ozone and surface UV in a changing climate, while H. RIEDER (Austria) explored the influence of climate warming, rising $\mathrm{CH}_{4}$ and reductions in $\mathrm{NO}_{\mathrm{x}}$ emissions on 21 st century U.S. surface ozone extremes. On a similar topic, T. BUTLER (Germany) presented a study using statistical modelling techniques to examine the importance of temperature and other meteorological parameters for predicting observed ozone concentrations in Europe.

Four talks explored the influence of ozone changes on climate. D. M. GILFORD (USA) used a radiative transfer model, satellite ozone observations, and reanalysis data to investigate the impact of the ozone radiative seasonal cycle on tropopause temperatures and the potential intensity of tropical cyclones. Using a coupled climate model, W. J. M. SEVIOUR (USA) explored the transient response of the Southern Ocean to stratospheric ozone depletion, which consists of an initial cooling followed by a long-term warming. Using a combination of a global climate model and an offline radiative transfer model, W. J. COLLINS (UK) showed that tropospheric ozone production and stratospheric ozone depletion have both contributed to historical increases in global precipitation. Finally, E. M. BERNARZ (UK) highlighted the importance of solar radiation-ozone feedback in modulating the atmospheric response to solar cycle forcing and stressed the importance of properly representing this process for fu- ture model studies of solar cycle forcing on climate.

\section{Global ozone observations and measurement tech- niques}

The Symposium's fifth session was dedicated to challenges and recent advances in ozone measurement techniques and observation networks, as well as data processing methodologies. Presentations on ground-based observations, airborne measurement platforms, as well as satellite remote sensing measurements of tropospheric, stratospheric and mesospheric ozone and related species, were given. Overall, there were 127 contributions to this session, making it the largest of the Symposium's sessions.

The first keynote talk, by V. THOURET (France), presented the IAGOS European infrastructure. IAGOS uses the potential of in-service aircraft to provide long-term observations of ozone and other atmospheric chemical compounds at the global scale. A number of talks addressed issues related to future observation capability and satellite stability requirements for long-term ozone trend detection (M. WEBER, Germany). In particular, limb-viewing satellites that can measure vertical trace gas profiles at high vertical resolution are currently aging, and only a few missions with limited Earth coverage or a small list of trace gases are in immediate planning (N. J. LIVESEY, USA). A longer term proposal for a compact limb satellite instrument was presented (D. FUSSEN, Belgium). Ozone observation networks on the ground are under great financial pressure, so several presentations covered new instrumentations that are cheaper to produce and can be operated more easily than current standard instruments (J. HERMAN, USA; Z. L. FLEMING, UK).

The second keynote talk, by A. THOMPSON (USA), reviewed the status of current networks providing ozone total column and profile observations (e.g. SHADOZ, NDACC, TOLNet). Several presentations focused on the validation and characterization of ozone and related trace gas observations and their uncertainties with both ground-based /in situ (A. W. DELCLOO, Netherlands; J. STAEHELIN, Switzerland; H. G. J SMIT, Germany; J. RIMMER, UK; R. SCHOFIELD, Australia; J. A. DIAZ, Costa Rica) or satellite (K. A. WALKER, Canada; N.A. KRAMAROVA, USA; J. H. KIM, Korea; E. KYRöLä, Finland; T. VERHOELST, BELGIUM) instruments. There have been increased efforts on the traceability of ozone remote sensing instruments to metrological standards, as shown from talks by L. EGLI (Switzerland) and T. LEBLANC (USA).

Ozone observations available from the various networks, airborne commercial platforms, as well as satellites, extend now to several decades. In order for the data to be useful for climate and trend studies, datasets need to be homogenized and merged in order to create long-term datasets. Several presentations discussed data merging (e.g. V. F. SOFIEVA, Finland; R. J. VAN DER A, Netherland; M. COLDEWEYEGBERS, Germany). A prerequisite for merging is a good understanding of biases and drifts (stability) in the individual datasets. Long-term satellite drifts are evaluated using coinci- 
dent ground-based measurements. A review of such drifts in stratospheric and mesospheric limb/occultation satellite measurements was presented by D. HUBERT (Belgium). In some cases, data assimilation or trajectory-mapping is used to extend the Earth coverage of merged datasets to regions where no observations are possible, for instance during polar night. In that context, G. A. LABOW (USA) presented an evaluation of the MERRA-2 assimilated ozone products. Finally, M. COYLE (UK) provided an overview on measuring ozone surface fluxes, which is critical to better understand tropospheric sinks and to constrain models.

The poster session, with over 100 posters, covered a wide range of ground-based and satellite observations, extending from historical datasets (e.g. 50 years of ozone observations in Hohenpeissenberg) to future instruments (e.g. SAGE III on the International Space Station) and studies of ozone trends as seen in remote locations, by ozone networks and global satellite datasets. Several improvements in both total ozone and ozone profile processing algorithms were introduced. A welcome trend is also to characterize carefully the observation uncertainties (e.g. several presentations on Brewer instruments as part of EUBREWNET EU-COST action).

\section{Effects of ozone on climate, human health, ecosystems and food production}

Ozone affects a wide range of environmental parameters, with both direct and indirect adverse effects on human health, ecosystem functioning and food production. This incorporates, for instance, climate interactions (effects of ozone depletion/recovery on surface climate), as well as effects of changes in climate variables (e.g., sea-ice extent, greenhouse gas emissions, biogeochemical cycles, etc.) on stratospheric ozone. Effects of changes in stratospheric ozone on health and ecosystems (terrestrial and aquatic), mediated through changes in surface ultraviolet radiation, present challenges in addition to effects of changes in stratospheric ozone on tropospheric ozone and, generally, air quality. Tropospheric ozone, which presents a risk to public health and ecosystems, is largely controlled by photochemical, physical and meteorological processes. Session 5 included contributions on topics addressing both direct and indirect ozone effects, their quantification with respect to human health, ecosystem services and biodiversity, and agricultural production and crop yields. There were 7 oral presentations and 13 posters in this session.

The session's keynote talk, presented by L. EMBERSON (UK), introduced the latest developments of modelling methods to assess the combined threat of ozone and climate extremes on ecosystems. She emphasized the benefits of using stomatal ozone flux to assess ozone effects, rather than ambient ozone concentrations, and also addressed some key remaining methodological limitations. She concluded that emerging advances in climate modelling using a combination of finer spatially and temporally resolved meteorological data in conjunction with new photosynthesis-based ozone deposition and stomatal flux models, will provide opportunities for a step change in how we assess ozone impacts.

F. SELTEN (Netherlands) elaborated on how the climate in a theoretical world without ozone might look, with impacts including lapse rate changes in the troposphere, the disappearance of the thermal tropopause, a strengthening of the Indian monsoon, a strong winter warming over eastern Canada and a cooling over Siberia. C. HEAVISIDE (UK) introduced an assessment of the health impacts due to short-term exposure of the population to ground-level ozone in the UK for the period 2001-14. The study showed that concentrations of ground-level ozone in the UK are highly related to emissions of precursor gases, and vary greatly across the UK, with large contrasts between urban and rural areas.

E. WOLFRAM (Argentina) showed that ozone-poor air masses transported from the Antarctic region to midlatitudes during spring/summertime increase UV radiation levels. The combination with higher solar elevation angles at solar noon at these latitudes induces additional increases in UV radiation. M. van WEELE (Netherlands) discussed satellite- and model-based decadal surface UV reconstructions, identifying extremes in UV index at northern midlatitudes that have been prevented by the Montreal Protocol, including the avoidance of potential societal impacts.

Finally, P. SAXENA (India) introduced the use of AOTX (accumulated exposure over a threshold of $X \mathrm{ppb}$ ) indices as a tool for the assessment of ozone impacts on plants in India. A study focusing on rice (Oryza sativa) crops in India concluded that, for most months in 2013, the AOT40 benchmark value set in Europe at 3000 ppb.h had been exceeded, stressing the need for defining national standards for assessing damage to crops from ozone. Posters for the session covered a similar range of topics, including aspects of UV, ozone effects on vegetation in specific areas such as mountain forests, and the effects of multiple pollutants interacting with ozone and the potential consequences for health.

\section{Future challenges for stratospheric and tropospheric ozone}

Following on from the discussions and questions motivated by the Symposium's talks and posters, two forwardlooking talks, by F. DENTENER (Netherlands) and J. PYLE (UK), set the scene for the panel discussion on the final day. They focused on future ozone research challenges, in the context of varying trends and emerging threats to human health and food security due to ozone effects, for instance in fastdeveloping regions in East and Southeast Asia.

Regarding stratospheric ozone, a future challenge will be to observe the predicted slow recovery from the decrease of halogenated ozone depleted substances. This decrease will occur in the context of climate change and the evolving ozone measurements system. Indeed, the future evolution of ozone will also crucially depend on the increasing abundances of $\mathrm{CO}_{2}, \mathrm{CH}_{4}$ and $\mathrm{N}_{2} \mathrm{O}$, and it will be driven by projected stratospheric circulation changes - an extremely challenging question for current observations. In the tropics in particular, the projected circulation-forced total ozone decrease can be 
masked by increases of tropospheric ozone. The impact on ozone of increases in the abundance of very short-lived halogenated substances (currently not controlled by the Montreal Protocol) will need to be quantified.

Regarding tropospheric ozone, only parts of the observed trends can be attributed to anthropogenic emissions changes, as there are substantial contributions from long-term variability. For policymaking, it will become increasingly important to better quantify the respective roles of natural processes and anthropogenic emissions changes.

In both cases, one of the main issues concerns the global system of measurements: will we have the observational capacity in place to detect future changes in both stratospheric and tropospheric ozone?

\section{Dialogue with policy decision-makers}

The concluding discussions focused on communication of the research findings to policy decision-makers. R. HARRABIN, the British Broadcasting Corporation's Environment Analyst, moderated a panel discussion, addressing future research challenges for ozone, and highlighting the relevance of communication at the science-policy interface. The final words were reserved for I. BOYD, Chief Scientific Adviser at the UK Department of Environment, Food and Rural Affairs, who reflected on the challenges of communicating complex scientific findings and uncertainties to policy decision-makers. 